\title{
Dança Educacional nas escolas públicas do Rio de Janeiro
}

\author{
Andrea Apolônia Pereira ${ }^{1}$ \\ Yara Lacerda ${ }^{2}$ \\ ${ }^{1}$ Universidade Castelo Branco, Rio de Janeiro, RJ, Brasil \\ ${ }^{2}$ Universidade Gama Filho, Universidade Estácio de Sá e (EMAA) do Centro Universitário \\ Celso Lisboa, Rio de Janeiro, RJ, Brasil
}

\begin{abstract}
Resumo: O objetivo deste estudo é identificar a intenção pedagógica e formativa de professores de educação física que levam seus alunos para participarem da Mostra Municipal de Dança da $2^{\mathrm{a}}$ CRE da cidade do Rio de Janeiro, considerando os propósitos e a especificidade do ensino da dança como componente curricular. A pesquisa classifica-se como descritiva e qualitativa. A amostra foi composta por onze professores de Educação Física Escolar atuantes na rede pública do município do Rio de Janeiro, no ensino fundamental, do $1^{\circ}$ ao $9^{\circ}$ ano da $2^{2}$ CRE. O instrumento de coleta de dados foi um questionário validado. Os resultados indicam que tanto existem professores orientando seus critérios de escolha baseados no interesse dos alunos e na habilidade, como os que incluem todos das turmas nos trabalhos. Constatou-se também haver ressentimento de alguns professores quando seus grupos não são escolhidos, preteridos por grupos de alunos especiais. Percebe-se que nem todos os professores encaram o evento como a culminância de um processo educacional no qual a dança é a ferramenta. Para esses a intenção é menos pedagógica e mais de espetáculo.
\end{abstract}

Palavras-chave: Educação Física Escolar. Dança. Ensino fundamental.

\section{Dance Education in Rio de Janeiro's public schools}

\begin{abstract}
The purpose of this study is to identify the teaching and training target of physical education teachers who take their students to participate in the Dance Municipality Exhibit of the 2nd CRE (Coordenadoria Regional de Educação - Regional Education Coordination) in Rio de Janeiro, considering the purposes and specificity of the teaching of dance as a curriculum element. The survey is classified as descriptive and qualitative. The sample was made up of eleven physical education teachers working in the public schools in the elementary school in the city of Rio de Janeiro, from the 1st to the 9th grade in the 2nd CRE. The instrument applied to collect data was a validated questionnaire. The results indicate that teachers are guiding their selection criteria based on students' interest or ability in performance, such as those that include all the class students in the works. It was also detected that there is resentment from some teachers when their groups are not chosen, left behind by groups of special students. It was observed that not all the teachers perceive the event as the peak of an educational process in which the dance is the tool. Those teachers think the goal of the event is much more show-oriented than teaching-directed.
\end{abstract}

Key Words: School Physical Education. Dance. Elementary School Teaching.

\section{Introdução}

A temática da Educação Física Escolar tem sido motivo de reflexão em muitas publicações do campo. Autores como Darido e Rangel (2005), Betti (1991), Kunz (1998), Resende, Soares e Moura (2009), entre outros, traçam por meio de suas obras um mapa sobre os vínculos existentes entre escola e a educação física. Este artigo também tem como objeto de estudo analisar as relações que se estabelecem entre processo educacional e a educação física escolar por intermédio da dança.

O foco de observação escolhido para analisar a relação escola e dança foi a Mostra Municipal de Dança do município do Rio de Janeiro, por congregar diferentes profissionais e estratégias de preparo das apresentações dos alunos. O objetivo que norteia esta pesquisa é identificar a intenção pedagógica e formativa de professores de educação física que levam seus alunos para participarem da Mostra Municipal de Dança da $2^{\mathrm{a}}$ Coordenadoria Regional de Educação (CRE) da cidade do Rio de Janeiro, considerando os propósitos e a especificidade do ensino da dança como componente curricular.

Algumas perguntas afloram a partir da temática proposta. Será possível encontrar no ensino fundamental atividades de dança que correspondam às estratégias educativas e não somente ao glamour das apresentações? Será que os professores que participam da Mostra Municipal de Dança preocupam-se que os 
processos pedagógicos de ensino-aprendizagem da dança sejam tratados à luz dos objetivos das aulas de Educação Física, já que a Mostra de Dança é uma atividade culminante onde o trabalho pedagógico desenvolvido pelos professores em conjunto com os alunos, bem como o nível de apropriação da cultura da dança por parte dos alunos, devem ser os focos privilegiados de atenção? Qual é a estratégia utilizada para a seleção dos alunos participantes? Será que o tipo de evento induz à cobrança do professor pela exibição performática dos alunos?

O estudo justifica-se pelas vivências no magistério e participação de uma das pesquisadoras na Mostra nos últimos três anos. Com base nas observações feitas ao longo deste tempo torna-se relevante discutir se a participação no evento faz parte de uma espetacularização e promoção da imagem da rede pública e da escola oficial ou se há preocupação efetiva com o processo educacional dos alunos nas aulas e com o preparo da apresentação propriamente dita.

\section{Metodologia}

Este estudo classifica-se como descritivo e qualitativo (THOMAS; NELSON, 2002). A população envolvida foi composta por professores de Educação Física Escolar atuantes na rede pública do município do Rio de Janeiro, no ensino fundamental, do $1^{\circ}$ ao $9^{\circ}$ ano. O critério de seleção foi feito mediante a participação dos docentes da $2^{\underline{a}}$ CRE, na Mostra Municipal de Dança, mesmo que recém chegado ao grupo de escolas participantes. Apesar do evento se realizar há 25 anos, não houve expectativa de delimitar um tempo específico de participação dos professores. A amostra envolveu onze indivíduos, que não representam a totalidade dos professores participantes da $2^{\mathrm{a}} \mathrm{CRE}$, mas sim os que se dispuseram a participar da pesquisa. Para Patton (1990 apud FLICK, 2007, p. 83) esse critério é denominado amostra de conveniência e refere-se "à seleção daqueles casos mais fáceis de serem acessados em determinadas condições [...] esse critério talvez represente o único caminho para se fazer uma avaliação com recursos limitados de tempo e pessoas".

A etapa de coleta de dados seguiu todos os procedimentos de autorização e controle exigidos pela Secretaria Municipal de Educação, com base na portaria E/DGED no 41/2009. Foi apresentado o projeto do estudo à coordenação da CRE, acompanhado do parecer do Comitê de Ética da Universidade Castelo Branco, atendendo 0 disposto na Resolução 196/96 do CNS. A entrada nas escolas ocorreu mediante a aprovação da CRE e das direções das escolas, quando os professores assinaram o termo de consentimento de participação na pesquisa, caracterizando o voluntariado.

O instrumento de coleta de dados foi elaborado com perguntas abertas e fechadas, categorizadas como: caracterização do grupo; impressões dos professores sobre a Mostra Municipal de Dança; processos pedagógicos de ensino-aprendizagem da dança na escola durante as aulas de Educação Física. O instrumento foi validado inicialmente por três professores doutores de duas instituições de ensino superior e, posteriormente, aplicado na forma de pré-teste em cinco professores, também participantes da Mostra de Dança, porém pertencentes a outra CRE não envolvida na pesquisa. Somente após esse processo foi realizada a coleta definitiva dos dados.

Além do questionário foi solicitada a técnica de evocação livre de idéias. Para Abric (1994 apud SÁ, 1998, p. 91) "A associação livre permite a atualização de elementos implícitos ou latentes que seriam perdidos ou mascarados nas produções discursivas".

\section{Descrevendo a Mostra Municipal de Dança}

A Mostra Municipal de Dança do Rio de Janeiro consiste em uma apresentação coreográfica de dança, anualmente realizada por alunos e orientada por Professores de Educação Física e de artes cênicas, sob a égide da Secretaria Municipal de Educação com o intuito de oferecer diferentes olhares sobre a formação educacional.

O projeto acontece há 25 anos e atribui-se a permanência e regularidade do evento a cada ano, à força da tradição que se criou fazendo-o resistir às inúmeras trocas de governos e propostas pedagógicas. Todas as unidades escolares das CRE podem participar, apresentando coreografias de dança. No município do Rio existem dez CRE, que reúnem, em média, 100 escolas grupadas por proximidade. Cada CRE organiza sua Mostra de Dança e seleciona as dez melhores coreografias para se reapresentarem em um segundo momento do evento, denominado pelos professores de "Mostrão"1. A iniciativa apresenta como objetivo, explicitado no regulamento

\footnotetext{
1 "Mostrão" foi um neologismo criado por uma das professoras investigadas para definir a última parte da apresentação considerada o grande final e é utilizado coloquialmente pelos docentes.
} 
distribuído como material informativo pela Secretaria Municipal de Educação (SME),

enriquecer o projeto pedagógico das escolas; reconhecer a dança como linguagem, manifestação artística e cultural; oportunizar acesso à linguagem da dança; compreender a dança como linguagem que contribui, significativamente, na formação do cidadão crítico, participativo e autônomo (CAVALCANTE, 2008, s/p).

Ainda segundo a SME, a Mostra objetiva

promover o intercâmbio entre as Unidades Escolares (UES) dos diferentes Conselhos Regionais Educacionais (CRES), pretende formar uma platéia solidária, capaz de prestigiar as produções apresentadas, avaliando-as criticamente e com sensibilidade (CAVALCANTE, 2008, s/p).

O evento é organizado em duas categorias de apresentação. A primeira, categoria $A$, é dividida em duas subcategorias: A1 correspondendo a um mínimo de $80 \%$ dos alunos com idade entre 4 e 7 anos completos no decorrer de 2008; e A2 com um mínimo de $80 \%$ dos alunos com idade entre 8 e 11 anos completos no decorrer do ano de 2008. A categoria B tem mínimo de $80 \%$ dos alunos com idade a partir de 12 anos completos.

A responsabilidade pela reserva de um teatro ou outro espaço adequado para a realização do evento é da CRE. As datas da Mostra são organizadas por categorias em dias ou em turnos diferentes, não excedendo em 15 o número de coreografias por turno e são acordadas com a coordenação da Mostra a fim de evitar coincidências de apresentações, o que dificultaria a ação da comissão responsável pelo acompanhamento. O tempo de apresentação de cada coreografia deve variar em torno de cinco minutos, com o mínimo de quatro e o máximo de oito minutos.

A CRE confecciona materiais a serem entregues à equipe dos projetos culturais que comparece às Mostras Regionais, contendo o nome de cada coreografia, o texto coreográfico, 0 nome da escola, o nome completo do professor, o número de alunos participantes e a duração da coreografia. As músicas das coreografias são gravadas em CD identificado, exclusivamente com a trilha sonora da cada coreografia e enviadas com antecedência. As dúvidas, divergências ou situações não previstas no regulamento são resolvidas pelo articulador de projetos culturais.

Essas informações são fornecidas pela SME em apostilas entregues nas escolas participantes. A cada ano são propostos temas de trabalho pela SME. Algumas das escolhas dos últimos anos foram: "Valorização da cultura afro-brasileira", Valorização das brincadeiras de rua" e "Respeito à Terra".

\section{Aspectos da dança como conteúdo curricular}

A construção deste artigo envolve aspectos da dança como conteúdo curricular e as dimensões formativas da educação em relação à Mostra de Dança. O ideal do aprendizado da dança na escola se traduz no ato de aprender em conjunto. Todos darem idéias, criarem e ensaiarem passos dentro dos seus próprios recursos é a proposta mais adequada para trabalhar o conteúdo. No decorrer das aulas os alunos não devem ser escolhidos por seus dotes físicos ou habilidades. Existe a possibilidade de desenvolver nos grupos, sob o estímulo do professor, a criatividade, o senso crítico, estético, os diálogos verbais, corporais e a participação. Esse tipo de construção coletiva permite, segundo Kunz (1998, p. 9), "oferecer diferentes respostas ao próprio questionamento, e só se pode realmente questionar aquilo em que se está corporalmente envolvido".

Para Savater (2005), o valor de educar está em contribuir para que o homem desenvolva

atributos como a compaixão pelo próximo, a solidariedade ou a benevolência pelos demais, que são considerados traços próprios de pessoas muito humanas, isto é, aquelas que saborearam o leite da ternura humana, segundo a bonita expressão shakespeariana (SAVATER, 2005, p. 21).

Embora o Brasil tenha avançado no campo educacional nas últimas décadas, ainda há muito a ser feito neste sentido. A Lei de Diretrizes e Bases da Educação (LDB), aprovada em 1996, trouxe avanços para o sistema educacional do nosso país, na medida em que visa a tornar a escola um espaço de participação social, valorização da democracia, de respeito, de pluralidade cultural e formação do cidadão (BRASIL, 1996).

A proposta dos Parâmetros Curriculares Nacionais (PCN) abordando como conteúdos da Educação Física, ginásticas, atividades rítmicas e expressivas, lutas e esportes no ângulo da cultura corporal, demonstra a intenção de harmonizar o desenvolvimento da criança e do jovem de maneira igualitária em diversas atividades, envolvendo o processo de ensino-aprendizagem em diferentes olhares e mergulhando-o na ótica da cultura corporal. Desenvolver-se considerando 
as linguagens oferecidas, cada uma delas representando um universo de possibilidades, potencializa o entrosamento do aluno com seu corpo, com sua forma de expressão e comunicação no mundo, ao mesmo tempo em que permite a valorização de suas experiências anteriores (BRASIL, 2000).

A literatura disponível na área propicia uma grande reflexão sobre as vantagens desses blocos de conteúdos serem trabalhados de forma equilibrada e coerente. Darido e Rangel (2005), assim como Moreira (2006), valorizam esse ponto de vista nas suas comunicações. Entretanto não é raro observar-se, na prática das escolas, registros monotemáticos, privilegiando 0 esporte em detrimento de outros conteúdos. Alguns pontos, tais como as danças e as lutas, permanecem à sombra das possibilidades de utilização ou são somente aproveitados por professores considerados experientes nesses temas.

No estudo da $2^{\text {a }}$ CRE, a observação se faz sobre as escolas municipais que promovem a dança, jogos coletivos entre outras atividades. As práticas se coadunam com a concepção dos PCN quando apontam a representação corporal, com características lúdicas, de diversas culturas, dando um novo significado à cultura corporal humana. Cada uma dessas manifestações de jogo, esporte, dança, ginástica e luta, é depositária de benefícios fisiológicos, psicológicos e de inúmeras possibilidades do corpo ser utilizado como meio de comunicação, de expressão nas perspectivas do lazer e da apropriação cultural. As propostas para a Educação Física escolar são elaboradas a partir deste princípio (BRASIL, 2000).

A diversidade cultural que caracteriza um país tem na dança uma de suas expressões significativas, constituindo uma ampla gama de possibilidades de aprendizagem. Pereira et al. (2001 apud GARIBA; FRANZONI, 2007) afirmam ser um dos conteúdos importantes a serem trabalhados na escola. Tal como os outros conteúdos ela permite que se potencialize a possibilidade dos alunos conhecerem a si próprios e aos outros, interagirem e explorarem o mundo da emoção, da imaginação, da criatividade por meio dos novos sentidos dos movimentos que Ihes são peculiares.

Vários tipos de danças são trabalhados no âmbito escolar. Incluem as manifestações que tem como características comuns a intenção de expressão e comunicação mediante gestos e a presença de estímulos sonoros para a realização do movimento, com base na cultura corporal da população, já que o processo educacional, do qual a educação física faz parte, deve considerar "o ser humano nas suas manifestações culturais relacionadas ao corpo e aos movimentos humanos, historicamente definidos" (DAÓLIO, 2004, p. 2).

As danças podem ser grupadas, evidenciando os contextos nos quais estão inseridas, tais como danças brasileiras: samba, baião, valsa, quadrilha, afoxé, catira, bumba -meu - boi, maracatu, xaxado, entre outras; danças urbanas: rap, funk, break, pagode, dança de salão; danças eruditas: clássicas, modernas, contemporâneas, jazz; danças e coreografias associadas a manifestações musicais: blocos de afoxé, Olodum, Timbalada, trios elétricos, escolas de samba; lengalengas; brincadeiras de roda, cirandas, escravos-de-jó (BRASIL, 2000).

Considerando a dança como mais uma ferramenta a ser utilizada na formação educacional da criança e do jovem, a Educação Física na Rede Escolar do Município do Rio de Janeiro, compartilha $o$ ideário de que este conteúdo pode e deve contribuir de forma significativa para 0 alcance de objetivos educacionais mais amplos. Como componente curricular da Educação Básica, a Educação Física vê a dança com possibilidades de estar totalmente integrada à proposta pedagógica das unidades escolares.

\section{Dimensões formativas da Educação \\ Física e as relações com a dança}

A prática pedagógica é atravessada pela construção do conhecimento, pela aprendizagem de fazeres e pela mudança de atitudes, provocada pelas transformações de cada aluno. Um exame sobre o papel tradicional atribuído ao ensino indica diferentes dimensões representadas pelo saber, saber fazer, saber ser e saber conviver, que correspondem aos aspectos conceituais, procedimentais e atitudinais. Em observações mais detalhadas, são identificadas nuances frente às diferentes áreas e conteúdos a serem ministrados nas escolas. Em alguns casos a realidade privilegia o saber e o fazer. Zabala (1998) preconiza que nas séries iniciais deve-se privilegiar o fazer e o ser, enquanto nos níveis mais adiantados o saber deve ser estimulado. Entretanto, o ser e o conviver correspondem à 
transformação proposta verdadeiramente pela educação, podendo considerar que, para haver transformação contida na dimensão atitudinal, o conhecimento, os fazeres e o conviver são imprescindíveis.

Em relação à dança na escola, tema deste estudo, a dimensão conceitual do conteúdo é evidenciada quando se proporcionam situações, nas aulas de Educação Física, para os alunos entrarem em contato com diferentes formas de danças, fornecendo informações e conhecimentos sobre como se apresentam na cultura popular brasileira ou em outras culturas.

A participação efetiva na Mostra de Dança permite a troca com outros professores e amplia a bagagem de conhecimento da criança e do jovem. É possível também, na dimensão conceitual, explorar as relações do trabalho com a dança nas escolas, considerando a forma como a mídia apresenta e incentiva a dança na cultura brasileira. Apresentar à criança diferentes tipos de dança que marcaram épocas, como o twist e o rock $n$ roll, na década de 60 , ou a lambada, na década de 90, permite ampliar as informações veiculadas, que podem até ser utilizadas, posteriormente, até para a criação de passos livres e espontâneos, favorecendo o aprendizado prático. As temáticas propostas pela SME para montagem dos espetáculos também podem ser exploradas em termos de conhecimento com informações que funcionem como base das ações coreográficas.

A dimensão procedimental do conteúdo da dança fica evidente na realização do trabalho prático com os movimentos que compõem os passos da coreografia, sejam movimentos propostos pelo professor ou criados e/ou modificados livremente pelas crianças. É também através da utilização de técnicas de imitação, para apresentar gestos espontâneos de movimentos.

Fazem parte do trabalho com dança no Ensino Fundamental estratégias utilizando o ritmo, através de palmas, de pequenos instrumentos, brincadeiras com música, atividades com sons, estalar dos dedos entre outros sons diferentes, atividades que envolvam o aprendizado do tempo, espaço e forma. Por meio delas, o fazer do aluno se fortalece.

A dimensão atitudinal é percebida na forma do aluno entender e se comportar diante da vida e das relações humanas. É possível discutir a questão do estereótipo que a dança geralmente representa para a maioria das pessoas como uma atividade somente feminina. Através dos trabalhos e dos estímulos ao questionamento, inúmeros assuntos são abordados pelo professor ao trabalhar com dança, contribuindo para minimizar preconceitos e ampliar horizontes. De acordo com estudo realizado por Fraga (1995), em escola pública de Cachoeirinha, Rio Grande do Sul, é possível discutir e criar experiências envolvendo meninos e meninas, a fim de potencializar o entendimento de um em relação ao outro e contribuir para desfazer concepções tais como dança para as meninas e futebol para os meninos. Nesses casos, a partir das discussões se objetiva modificar a conduta e a discussão de gênero pode ser entendida na esfera da dimensão atitudinal.

Atitudes que podem ser trabalhadas com 0 ensino da dança nas aulas de educação física, como a cooperação, a participação, a autoestima, o respeito pelas diferenças e pelo outro, tornamse evidentes quando o aluno se modifica perante o contexto educacional por ele vivido. São exemplos do saber conviver.

É possível entender as dimensões conceituais, procedimentais e atitudinais contidas na Mostra de Dança ao se apresentar os diferentes tipos de dança em regiões do Brasil, mostrar os tipos de culturas existentes, valorizar as várias formas de movimentos e danças apresentadas na nossa cultura, estimular a participação de todos os alunos nas coreografias e observar as mudanças e transformações ocorridas.

\section{Apresentação e discussão dos resultados}

A discussão dos dados foi feita à luz da análise de conteúdo apoiada em Vala (SILVA; PINTO, 1989), Bardin (1995) e Sá (1998), para quem essa técnica é adequada para diferentes tipos e níveis de pesquisa empírica.

\section{Perfil do grupo}

A caracterização do grupo apresentou somente mulheres, com média de idade de 41,78 anos e 19,81 anos de formadas; o tempo de atuação no município foi de seis anos e a participação média na Mostra de Dança de 7,18 anos (Tabela 1). O predomínio de tempo de atuação na esfera escolar pública do município correspondeu aos períodos de três a oito anos e a mais de oito anos. 


\begin{tabular}{ccccc}
\hline $\begin{array}{c}\text { Docente } \\
\text { s }\end{array}$ & Sexo & Idade & TF & Tempo de MD \\
\hline 1 & F & 55 & 34 & 12 \\
2 & F & 33 & 11 & 3 \\
3 & F & 35 & 15 & 7 \\
4 & F & 53 & 30 & 18 \\
5 & F & 46 & 24 & 1 \\
6 & F & 47 & 28 & 10 \\
7 & F & 40 & 17 & 3 \\
8 & F & 31 & 8 & 4 \\
9 & F & 39 & 16 & 1 \\
10 & F & 40 & 17 & 10 \\
11 & F & 40 & 18 & 11 \\
\hline Total & - & 459 & 218 & 80 \\
\hline Média & - & 41,72 & 19,81 & 7,18 \\
\hline DP & - & 7,76 & 8,15 & 5,41 \\
\hline
\end{tabular}

Tabela 1. Perfil dos docentes segundo sexo, idade, tempo de formado (TF) e tempo de participação na Mostra de Dança (MD)

A qualificação dos docentes apresentou $9 \%$ tendo apenas a graduação, $64 \% \mathrm{com}$ diploma de especialista, lato sensu e $27 \%$ tendo feito o stricto sensu na área da motricidade humana (Tabela 2). As especializações registradas variaram entre treinamento esportivo, psicomotricidade, educação física escolar e apenas dois professores na dança. Em relação à aproximação com o universo da dança como bagagem de experiência de vida, $46 \%$ relataram terem sido formadas na dança com influências desde tenra idade e $54 \%$ não possuíam intimidade com a prática.

Em relação à qualificação dos professores abordados o maior percentual foi relativo ao lato sensu, compreendendo cursos de dança, treinamento desportivo e psicomotricidade.

\begin{tabular}{cc}
\hline Caracterização da Amostra & $\%$ \\
\hline De 3 a 8 anos & 36 \\
+ de 8 anos & 64 \\
\hline Grau de Instrução & $\%$ \\
\hline Graduação & 9 \\
Lato Sensu & 64 \\
Stricto Sensu & 27
\end{tabular}

Tabela 2. Tempo de Atuação no Município (TM) e grau de instrução

\section{Impressão dos professores sobre a Mostra de Dança - Associação de idéias}

A subjetividade dos professores em relação às impressões gerais sobre o evento foi investigada por meio da técnica de associação de idéias, tendo como estímulo a expressão "Mostra de Dança". Foram citadas três palavras por cada participante (Quadro 1).

Quadro 1. Palavras citadas pelos professores

\begin{tabular}{|l|l|l|l|}
\hline & \multicolumn{1}{|c|}{$1^{\underline{a}}$ palavra } & \multicolumn{1}{c|}{$2^{\underline{a}}$ palavra } & \multicolumn{1}{c|}{$3^{\underline{a}}$ palavra } \\
\hline 1 & Desorganização data & Política p/grupos dança & Agradar o aluno/medalha troféu \\
\hline 2 & $\begin{array}{l}\text { Aluno/autoestima- } \\
\text { Prof/ trabalho }\end{array}$ & $\begin{array}{l}\text { Aluno/participação } \\
\text { Prof./desorganização }\end{array}$ & $\begin{array}{l}\text { Aluno/cidadania } \\
\text { Prof./frustração }\end{array}$ \\
\hline 3 & Desafio & Superação & Criatividade \\
\hline 4 & Trabalho & Encantamento & Decepção \\
\hline 5 & Expressão & Movimento & Criatividade \\
\hline 6 & Perseverança & Sacrifício & Dedicação \\
\hline 7 & Ritmo & Plasticidade & Beleza \\
\hline 8 & Movimento & Alegria & Compartilhar \\
\hline 9 & Expressão & Comunicação & Movimento \\
\hline 10 & Diversidade & Cultura & Criatividade \\
\hline 11 & Oportunidade & Formação de caráter & Beleza, estética e autoestima \\
\hline
\end{tabular}

Formaram-se quatro grupos para as associações feitas, considerando a similaridade dos sentidos dados às palavras, que permitiram vislumbrar, a partir da idéia contida, categorias centrais e o que o evento significava para os docentes abordados. Cada um dos grupos ficou caracterizado pela palavra mencionada mais vezes e revelou nuances percebidas pelos participantes. Os grupos contendo maior número de palavras foram o primeiro, seguido pelo terceiro, encabeçados pelas categorias movimento e autoestima respectivamente, seguidas por cidadania e frustração (Quadro 2). 
Quadro 2. Categorização das associações de idéias

10 GRUPO- Movimento (3)/expressão (2)/ritmo (1)/comunicação (1)/plasticidade

(1)/criatividade(3)/beleza-estética(2) TOTAL 13

2 GRUPO - Cidadania (1)/formação de caráter (1)/diversidade (1)/cultura (1)

3o GRUPO- Auto estima (2)/desafio (1)/perseverança (1)/oportunidade(1)/superação (1)/

sacrifício(1)/alegria(1)/encantamento/(1)/trabalho(2)/participação(1)/dedicação(1)/compartilhar(1)

TOTAL 12

4음 GUPO - Frustração (1)/desorganização(2)/decepção(1).

A categoria movimento parece estar relacionada à prática representando a dimensão procedimental, e cidadania e autoestima à atitudinal. Supõe-se que frustração esteja vinculada ao impacto psicológico provocado pela Mostra de Dança. Associações à frustração, desorganização e decepção foram das professoras 2 e 4 . A professora 2 manifestou frustração

porque são escolhidas três coreografias para uma apresentação final e, na maioria das vezes, as escolhidas pertencem ao Núcleo de Dança, que possui espaço próprio para a prática da dança, além de aulas com profissionais especializados durante $o$ ano todo.

A professora argumenta ser injusta e desigual a competição das escolas do Núcleo de Dança com as demais escolas da rede que não possuem enfoque específico e às vezes nem espaço físico para trabalhar. Entretanto, apesar das escolas possuidoras de núcleos de dança levarem vantagem, o critério de escolha dos grupos eleitos pelos representantes da SME não parece ser o da estética padronizada. Grupos compostos por alunos com diferentes tipos de necessidades especiais são valorizados pelo órgão governamental.

\section{Relações aulas de dança na escola e apresentação da Mostra de Dança}

As aulas destinadas aos ensaios para a apresentação são dadas pelos professores em horários especiais e separados. Somente dois utilizam o tempo de aula, trabalhando integralmente para o espetáculo. Não são todos os alunos que participam dos ensaios nesse caso há um distanciamento da proposta de integração no cotidiano das aulas.
Em relação à Mostra de Dança, é identificada a presença e participação de alunos especiais, podendo ser caracterizada como integrativa. Muitos professores afirmam "todos que manifestarem interesse em dançar são bemvindos na apresentação" (Prof. 3, 4, 5, 6, 7, 9, 10, 11). O ideal é que a participação dos alunos seja importante em todo processo de formação e ensaios da coreografia. Quando o professor elege somente os que se apresentam, deixa de envolver os que não se interessam espontaneamente.

A inclusão somente ocorreria se houvesse qualificação e preparo adequado dos docentes envolvidos no processo educacional, estrutura das escolas e outro contexto que pudesse ser efetivamente denominado de inclusão escolar. A inclusão ocorre quando há escola de qualidade para todos, deficientes ou não, habilidosos ou não. Essa concepção é corroborada por Mantoan (2007) para quem "O princípio democrático da educação para todos só se evidencia nos sistemas educacionais que se especializam em todos os alunos, não apenas em alguns deles, os alunos com deficiência" (s/p).

A professora 2 manifestou 0 descontentamento em relação ao fato de grupos de alunos com necessidades especiais se apresentarem e algumas vezes, serem considerados os melhores da Mostra de Dança. Também a professora 4 trabalha com o critério de habilidades para a performance e relata decepção por considerar injustiça não ser escolhida. Além dela, outros docentes (1, 8 e 10) baseiam os critérios de formação dos grupos discriminando os menos habilidosos. 
Essas professoras consideram a Mostra de Dança regida pela dimensão estética e performática, quando o princípio da educação inclusiva é valorizar a diversidade humana, abandonando a visão de tornar o aluno normal para contribuir para o mundo (MANTOAN, 2009).

Os relatos deixam entrever a visão dos docentes ora de forma dissimulada, ora clara:

"os alunos se inscreviam no projeto e para a Mostra só os melhores" (Prof. 1);

"é realizada uma seleção daqueles que tem maior aptidão para a dança pré selecionada. Depois pode entrar quem quiser, se houver tempo hábil" (Prof. 8);

"os que tem interesse pelo movimento corporal e estético" (Prof. 10).

Nesse sentido, critica-se a atitude dos professores, preocupados com a performance na hora do espetáculo, e não com os processos pedagógico e formativo vivenciados pelos grupos, até chegarem ao momento da exposição pública. Idéia essa confirmada por Darido e Rangel (2005) ao afirmarem que o princípio da inclusão ou da não exclusão "procura garantir o acesso de todos os alunos às atividades propostas" (p. 38), demonstrando que o mais relevante é a participação democrática e inclusiva e não a preocupação técnica. Também Savater (2005) destaca que um dos principais aspectos que a educação transmite é que não somos únicos no mundo, apesar de sermos singulares e que nossa condição implica considerar os nossos parentes humanos. Para isso ocorrer, é necessário identificar e respeitar as diferenças existentes entre todos.

A opinião dos professores sobre a participação dos alunos é muito positiva. Os relatos foram de entusiasmo, conquista coletiva, valorização pessoal, compromisso, experiência ímpar e interesse:

\begin{abstract}
"eles ficam maravilhados, é um grande incentivo e estímulo para a valorização pessoal e conquista como grupo" (Prof. 3);

"eles se sentem valorizados, compromissados e responsáveis por um projeto" (Prof. 6);

"eles adoram ficar esperando as novidades de cada ano" (Prof. 7);

"eles gostam muito de participar da Mostra de Dança. O nível de animação dos ensaios e da preparação é altíssimo. Os alunos curtem todo o processo" (Prof. 8).
\end{abstract}

A organização das escolas envolve muito mais o empenho dos professores do que as iniciativas institucionais. O engajamento das professoras no evento é grande, apesar das dificuldades em termos materiais, ambientais para as aulas, pois com freqüência os professores se deparam com a falta de espaço adequado para o trabalho cotidiano e também para os ensaios. Em termos organizacionais do evento há queixas relacionadas aos transportes, entretanto os professores admitem que todos ajudam como podem.

As dimensões conceituais, procedimentais e atitudinais estão presentes no trabalho vivenciado pelos alunos e na percepção dos professores, apesar de não ser utilizada essa nomenclatura por parte dos docentes abordados. Como são feitas propostas temáticas pela $\mathrm{CRE}$, que unificam a apresentação, os aspectos conceituais são representados pelo conhecimento gerado pelo próprio tema. Para a montagem da apresentação é necessário que o levantamento sobre informações adequadas a cada assunto proposto seja realizado. Em 2009, a $2^{\text {a }}$ CRE sugeriu vários temas relacionados aos projetos político-pedagógicos das escolas.

A dimensão procedimental que envolve aprender a fazer, naturalmente valoriza criar o movimento e realizá-lo. Sem isso não há apresentação do trabalho.

A dimensão atitudinal, a mais presente na fala dos professores, detecta os valores identificados em relação ao trabalho realizado e se expressa nas categorias cidadania e autoestima. Surgem no estímulo à responsabilidade, respeito, espírito de equipe, socialização, comprometimento, cooperação, união e disciplina.

Atribui-se essa valorização ao nível de motivação dos grupos que superam as dificuldades independendo de quais elas sejam. As queixas mais frequentes dos professores foram em relação à falta de espaço apropriado para aulas e ensaios, falta de investimento da escola, falta de incentivo das direções, verba, condução para transportar os alunos no dia das apresentações e pouca tolerância dos outros professores que reclamam do barulho e eventuais inconvenientes que ocorrem por ocasião dos ensaios.

\section{Considerações Finais}

A Mostra Municipal de Dança destaca-se no cenário de propostas pedagógicas, no âmbito da escola pública da cidade do Rio de Janeiro como 
evento que conquistou respeito e credibilidade. $\mathrm{O}$ empenho dos professores e alunos participantes demonstra o envolvimento no evento.

No grupo investigado foi identificado que os docentes se sentem motivados a participar da Mostra. O grupo ficou dividido entre os que introduzem todos os alunos nas aulas e nos ensaios e os que privilegiam os mais habilidosos para a apresentação.

Os docentes que conduzem suas aulas pensando no evento apresentam como característica orientar seus critérios de escolha baseados no interesse dos alunos ou na habilidade de performance. $\mathrm{Na}$ percepção construtivista da educação, pode-se afirmar que não são todos os professores que percebem a possibilidade de utilizar a dança como uma linguagem de aprendizagem criativa, aproveitando a bagagem trazida pela vivência do aluno. Esses optam pelo tradicional esquema performático onde o aluno copia o que é oferecido de forma já pronta.

Há ressentimentos e frustrações aparentes na fala do professor 2, quando seus grupos não são escolhidos, preteridos por grupos de alunos especiais, haja vista que a SME considera merecedor de premiação todo e qualquer trabalho apresentado.

A parcela dos professores que decide escolher apenas os melhores para participarem das coreografias parece manter-se à margem da política pública de não exclusão, no afã de mostrar trabalhos esteticamente mais apresentáveis. Parece não encararem o evento como a culminância de um processo educacional no qual a dança é a ferramenta.

Entretanto outros respeitam as dificuldades dos alunos e por isso mesmo inserem todos no trabalho e oportunizam momentos de crescimento aos grupos trabalhados permitindo que eles próprios criem suas movimentações, façam suas escolhas musicais e exponham suas possibilidades de perceber e dominar 0 movimento.

No discurso dos professores participantes da Mostra estão presentes valores como ética, respeito, comprometimento, cooperação companheirismo entre outros definidores da construção de indivíduos cidadãos, que caracterizam a dimensão atitudinal proposta no olhar educacional. Entretanto nem sempre é manifestada a intenção pedagógica e formativa dos alunos por meio do conteúdo dança. A Mostra de Dança Municipal da $2^{\text {a }}$ CRE reflete o caminho encontrado por cada professor para cumprir sua tarefa pedagógica.

Permanece a pergunta se o tipo de evento com sistema de premiação dos melhores induz a esse processo de montagem onde o professor, por se esforçar em fazer o que consideram uma boa apresentação, se despreocupa com a função da dança como componente curricular.

\section{Referências}

BARDIN, L. Análise de conteúdo. Lisboa: Edições 70, 1995.

BETTI, M. Educação Física e sociedade. São Paulo: Movimento, 1991.

BRASIL. Ministério da Educação e do Desporto. Lei no 9.394, de 20 de dezembro de 1996: estabelece as diretrizes e bases da educação nacional. Brasília, 1996. Disponível em: http://www.rebidia.org.br/direduc.html Acesso em: 15 ago.2009.

Parâmetros Curriculares Nacionais: educação física. Secretaria de educação fundamental. $2^{\underline{a}}$ ed. Rio de Janeiro: DP\&A, 2000.

CAVALCANTE, N. Regulamento Mostra de dança. Prefeitura da cidade do Rio de Janeiro, 2008.

\section{DAÓLIO, J. Educação Física e o conceito de} cultura. Campinas: Autores Associados 2004.

DARIDO, S. C.; RANGEL, I. C. A. Educação

Física na escola: implicações para a prática pedagógica. Rio de Janeiro: Guanabara Koogan, 2005.

\section{FLICK, U. Uma introdução à pesquisa} qualitativa. 2 ed. Porto Alegre: Bookman, 2007.

FRAGA, A. B. Concepções de gênero nas práticas corporais de adolescentes. Movimento, ano 2, n. 3, 1995/2, p. 35-41. Disponível em: http;//ufrgs.br/esef Acesso em: 12 maio 2009.

GARIBA, C. M. S.; FRANZONI, A. Dança escolar: uma possibilidade na Educação Física.

Movimento, Porto Alegre, v. 13, n. 2, maio/agosto, 2007, p. 155-171. Disponível em: http://ufrgs.br/esef Acesso em: 12 maio 2009.

KUNZ, E. (Org.). Didática da Educação Física I. ljuí: Unijuí, 1998. 
MANTOAN, M. T. E. Integração $\mathbf{X}$ inclusão:

escola (de qualidade) para todos. Laboratório de Estudos e Pesquisas em Ensino e Reabilitação de Pessoas com Deficiência - LEPED, Campinas, Unicamp, 2007. Disponível em> http://www.proinclusao.org.br Acesso em 6 dez. 2009.

MOREIRA, E. C. (org.). Educação Física Escolar, desafios e propostas 2. Jundiaí: Fontoura, 2006.

RESENDE, H. G. de; SOARES, A. J. G. S.; MOURA, D. L. Caracterização dos modelos de estruturação das aulas de educação física.

Motriz, Rio Claro, v.15, n.1, jan./mar. 2009, p. 3749. Disponível em:

http://www.rc.unesp.br/ib/efisica/motriz/revista.htm Acesso em: 20 out. 2009.

SÁ, C. P. de. A construção do objeto de pesquisa em Representações Sociais. Rio de Janeiro: Ed. UERJ, 1998.

SAVATER, F. O valor de educar.São Paulo: Planeta do Brasil, 2005.

THOMAS, J. R.; NELSON, J. K. Métodos de pesquisa em atividade física. $3^{\mathrm{a}}$ ed. Porto Alegre: Artmed, 2002.

VALA, J. A análise de conteúdo. In: SILVA, A. S.; PINTO, J. M. (orgs.). Metodologia das ciências sociais. Porto: Afrontamento, 1989.

ZABALA, A. A prática educativa: como ensinar. Porto Alegre: Artes Médicas, 1998.

\section{Endereço:}

Yara Lacerda

Rua Manoel Vitorino, 625 Piedade

Rio de Janeiro RJ Brasil

20.748-900

Telefax: (21) 2575.8226

e-mail: yaralacerda@superig.com.br

Recebido em: 5 de setembro de 2009.

Aceito em: 10 de março de 2010.

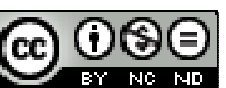

Motriz. Revista de Educação Física. UNESP, Rio Claro, SP, Brasil - elSSN: 1980-6574 - está licenciada sob Licenca Creative Commons 